\title{
Imaging Findings of Benign Enhancing Foramen Magnum Lesions
}

W e are grateful to McGuinness et al for their interesting and clinically applicable article "Benign Enhancing Foramen Magnum Lesions: Clinical Report of a Newly Recognized Entity." In a series of 14 patients, the authors documented the stereotypical appearance of 16 small, enhancing lesions posterior to and separate from the proximal intracranial vertebral artery. In all patients with available imaging, longitudinal follow-up confirmed stability. The authors noted 9 cases in which the enhancing focus was continuous with a presumed bridging vein extending from the internal vertebral venous plexus to the anterior condylar venous confluence. Thus, they suggested that the process might reflect a venous finding, such as a varix, with a small nerve root ganglion/pseudoganglion as a differential consideration.

We recently observed this same finding in a 67-year-old man undergoing a radiation treatment-planning brain MR imaging for a right caudate melanoma metastasis (Fig 1A). The presence of a small (2-mm), enhancing left foramen magnum lesion (Fig 1B) initially generated concern for a second metastasis. However, after we retrieved the patient's prior MR imaging (Fig $1 C$ ), our concern was mitigated by 18 -month stability. We were further reassured after noting its appearance was identical to that of the patients of McGuinness et al, supporting the benign nature of the process, despite metastatic disease elsewhere.

The imaging in our patient illustrates several additional notable features. First, he had a prior contrasted soft-tissue neck CT (Fig 1D), on which the process was evident as a small enhancing focus with an attenuation measurement of approximately 90 Hounsfield units. This was less than surrounding arterial vascular structures (for instance, $175 \mathrm{HU}$ in the adjacent vertebral artery) and lower than the intracranial dural venous sinuses (for instance, $190 \mathrm{HU}$ in the transverse sinus). However, its attenuation was similar to that in the upper cervical epidural plexus, suggesting a related venous etiology. Second, while the authors noted that they were unable to visualize the relationship of the process to the

http://dx.doi.org/10.3174/ajnr.A5330 spinal accessory or upper cervical nerve roots, our patient's thinsection postcontrast imaging reveals its proximity to the latter (Fig $1 E$ ). While this could suggest a neural or perineural origin, we likewise referenced the findings of prior anatomic studies, in which small bridging veins approximate nerve roots as they course to and through the surrounding dura. ${ }^{2-4}$ Thus, the spatial relationship between the lesion and the upper cervical nerve roots does not preclude a venous etiology of the process. Last, our patient had a large developmental venous anomaly in the left cerebellum (Fig $1 F$ ), superior to the foramen magnum finding, but we suspect this may be coincidental in nature.

Regardless of its specific etiology, we hope that our case illustrates complementary features that can assist radiologic interpretation. Whether observed on CT or MR imaging, the stereotypical imaging characteristics are reassuring, and their recognition can optimize resource allocations by obviating extensive follow-up imaging, even when assessing intracranial metastatic disease.

Disclosures: M. Vittoria Spampinato-UNRELATED: Grants/Grants Pending: Bracco*. *Money paid to the institution.

\section{REFERENCES}

1. McGuinness BJ, Morrison JP, Brew SK, et al. Benign enhancing foramen magnum lesions: clinical report of a newly recognized entity. AJNR Am J Neuroradiol 2017;38:721-25 CrossRef Medline

2. Krings T, Geibprasert S. Spinal dural arteriovenous fistulas. AJNR Am J Neuroradiol 2009;30:639-48 CrossRef Medline

3. Krings T, Mull M, Bostroem A, et al. Spinal epidural arteriovenous fistula with perimedullary drainage: case report and pathomechanical considerations. J Neurosurg Spine 2006;5:353-58 CrossRef Medline

4. Thron A, Krings T, Otto J, et al. The transdural course of radicular spinal cord veins: a microangiographical and microscopical study. Clin Neuroradiol 2015;25:361-69 CrossRef Medline

(D) M.U. Antonucci (1) M.V. Spampinato Department of Radiology and Radiological Science Medical University of South Carolina Charleston, South Carolina 


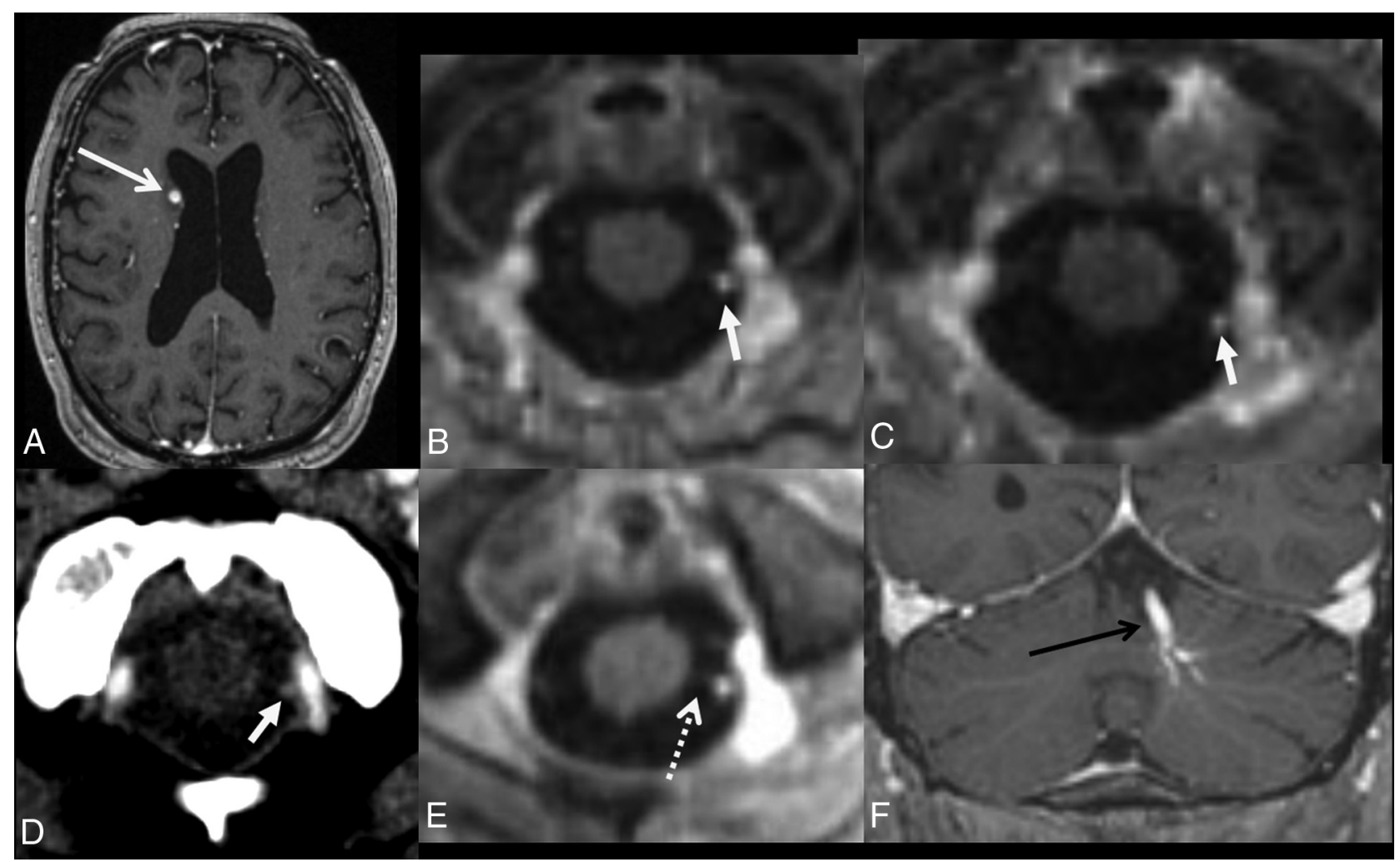

FIG 1. Axial T1 postcontrast volumetric imaging from a radiation-planning MR imaging for a metastatic melanoma lesion ( $A$, arrow) demonstrates a 2-mm enhancing focus posterior to the left vertebral artery in the foramen magnum ( $B$, arrow). This was unchanged from a study 18 months earlier (C, arrow) and was seen on a venous phase soft-tissue neck CT ( $D$, arrow). Thin-section postcontrast imaging reveals its close proximity to a barely perceptible upper cervical nerve root ( $E$, dashed arrow). A presumably coincidental developmental venous anomaly is seen in the left cerebellar hemisphere ( $F$, black arrow). 